Tyndale Bulletin 71.1 (2020) 19-42

\title{
IS THE MASORA CIRCULE, TOO, AMONG THE SCRIBAL HABITS?
}

\author{
Kim Phillips \\ (klp31@cam.ac.uk)
}

\begin{abstract}
Summary
Research into masoretic biblical manuscripts (MSS) is heavily reliant on our ability to reunite fragments once belonging to the same codex, now separated one from the other in the Genizah morass, and to identify the scribes behind codices whose colophons have been lost. This task is made especially difficult by the fact that the oriental square hand in which these codices were written is highly stereotypical. Consequently, the paleographer must rely on paratextual features: non-textual features that accompany the biblical text itself, which form a kind of fingerprint for each MS or scribe. This article argues that the masora circule (the small circule used in these MSS to link the masoretic notes to the biblical text itself) functions as part of this unique fingerprint.
\end{abstract}

\section{Introduction}

Despite the huge amount of labour already invested by dedicated scholars over the past centuries, the work of gathering, describing, and analysing the biblical MSS from the close of the masoretic era is still in its infancy. Consequently, many large questions remain without sufficient data or evidence. Can we specify the nature of the interaction between the Babylonian and Tiberian masoretic traditions? Can we trace out the process of development of the system of masoretic notes? Were the Masoretes Qaraites, Rabbanites, or from either sect? Are the biblical texts from these sects different one from the other, and, if so, in what ways? Are there distinguishable schools of thought and practice among those who claim to follow the illustrious Ben Asher? For that 
matter, when, where, and why did the reputation of Ben Asher become illustrious? What happened to Ben Naphtali? These and many, many other questions - textual/masoretic, codicological, historical, and cultural - are still wide open.

At the most practical level, fully orbed answers to these questions are reliant on two vast prior palaeographic-codicological undertakings: (1) the 25,000 Genizah Bible fragments must be regrouped and individual fragments must be reunited with other fragments from the same codex or scroll; ${ }^{1}$ (2) in the absence of colophons, individual codices or parts of codices (including the hundreds of early examples in the Firkowich collection) must be allocated, as far as possible, to scribes whose names, dates, whereabouts, and styles are known from other, colophon-carrying, codices.

Regrouping fragments, and identifying the scribe behind uncolophoned codices, is especially difficult in the case of medieval Bible codices from the East. As has been repeatedly stipulated by palaeographers such as Malachi Beit-Arié, Hebrew scribal practice within a particular geographical region and period is frequently highly stereotypical. $^{2}$ This is particularly the case with Bible MSS. The majority of Bible fragments in the Genizah collections originate from Eastern MSS, whose separate hands - particularly in fragments from monumental codices - can be extremely difficult to distinguish. ${ }^{3}$

In light of the great difficulty in isolating individual scribes on the basis of handwriting alone, Beit-Arié advocates paying attention to the

1 Great gains have been made in recent years in the task of finding possible Genizah MS joins by the application of digital facial recognition techniques to the Genizah fragments. See, for example, L. Wolf, L. Litwak, N. Dershowitz, R. Shweka, and Y. Choueka, 'Automatically Identifying Join Candidates in the Cairo Genizah', International Journal of Computer Vision 94:1 (2011): 118-35. For a less technical description, see B. Outhwaite, 'Completing the Jigsaw: Digitally Matching Fragments in the Genizah', Cambridge University Libraries Information Bulletin NS 68 (2011): 913. However, due to the particular difficulties associated with oriental model Bible codices, it is doubtful that the computer will replace the human in this particular task any time soon.

2 On the division of the codicology and scripts of Hebrew books into distinct geographical-cultural regions, see Malachi Beit-Arié, Hebrew Codicology: Historical and Comparative Typology of Medieval Hebrew Codices based on the Documentation of the Extant Dated Manuscripts until 1540 Using a Quantitative Approach: Preprint internet version 0.12 [Hebrew] (2020): 63-73. Available at http://web.nli.org.il//NLI/ Hebrew/collections/manuscripts/hebrewcodicology//Hebrew-Codicology-continuouslyupdated-online-version.pdf.

3 On the uniformity of script among early oriental Bible codices, and some of the cultural forces behind this uniformity, see Beit-Arié, Codicology, 386. 
paratextual scribal elements in any particular MS. These include features such as the different means a scribe may employ to ensure left justification of a column of text, or the manner in which a scribe abbreviates the Tetragrammaton. Beit-Arié claims that in any geographical region and chronological period a range of possibilities existed for each paratextual function (though in practice, a small subset of this range may have been highly dominant). Consequently, for each paratextual task a scribe would choose from the range of options available to them. The complete, and idiosyncratic, toolkit thus built up by an individual scribe thus becomes a vital tool for the modern palaeographer in the task of identifying, and distinguishing between, scribes, and reuniting separated fragments from the same codex. ${ }^{4}$

Beit-Arié's Codicology encompasses many different types of medieval Hebrew MSS. Naturally, therefore, not all of the paratextual elements he discusses are germane to biblical codices. Nevertheless, in recent years more and more paratextual features specifically pertaining to masoretic biblical codices have been identified. ${ }^{5}$ Frustratingly, many of these paratextual features pertain to the writing of the Masora Magna (MM) notes, and these (being written in the top and bottom margins of the page, which are frequently the first places to suffer damage) are often missing or severely mutilated. Ideally, further paratextual elements will be identified that are located in and among the biblical text itself. This is the topic of the present article.

This article attempts to justify the claim that the masora circule (the small circle used to 'connect' a Masora Parva [MP] note to the biblical text to which it refers; see $\$ 2$ below) can be used as an additional paratextual element for the purposes of rejoining separated leaves from a single codex and identifying further examples of a known scribe's work. Below, seven different facets of the use of this circule are identified and discussed. It will be shown that in each of these seven cases, the scribe or masran ${ }^{6}$ had the opportunity to exercise a measure

4 Beit-Arié, Codicology, 387-94.

5 See, for example, Yosef Ofer, 'Masoretic Matters: The Marking of the Parashiyyot' [Hebrew], Megadim 2 (1986-1987): 91-104 and the discussions in Kim Phillips, 'Two New Fragments from the Scribe behind the Leningrad Codex' in Research Approaches in Hebrew Bible Manuscript Studies: Proceedings of the EAJS LAB Conference, 6-8 June 2016, Aix-en-Provence (Studies in Jewish History and Culture; Leiden: Brill, forthcoming): n.p.p. and Kim Phillips, 'A New Codex from the Scribe behind the Leningrad Codex: L17', Tyndale Bulletin 68.1 (2017): 1-29.

6 That is, the scholar responsible for adding the masoretic notes to the biblical text. Sometimes this was the same scribe who wrote the consonantal text (as was the case, 
of intentionality, individuality, and idiosyncrasy in the manner in which they employed the masora circule. ${ }^{7}$ In particular, evidence is provided in support of four claims: (1) for each of the seven facets of circule use discussed below, a range of practices are found in different MSS; (2) each MS displays a reasonable level of consistency regarding its particular practices pertaining to circule placement; (3) when taken together, these seven facets demonstrate significant capacity to distinguish between different biblical codices; (4) as far as is demonstrable with the limited evidence currently available, scribal habits pertaining to circule placement remain sufficiently consistent across different productions by the same scribe for this to be a useful tool in the task of identifying other productions by that same scribe.

Seven high-quality oriental masoretic Bible codices from the 10th and 11th centuries were consulted for the purposes of the following discussion: A, DP, EVR I Bibl. 54, L, L17, L20, and Or. 4445. ${ }^{8}$ Two of

for example, in the production of the Leningrad Codex). Sometimes, though, one scribe would write the consonantal text, and another would add the vocalisation, accentuation, and masoretic notes. This was the case, for example, in the production of the Aleppo Codex (A). See Israel Yeivin, Introduction to the Tiberian Masorah, ed. E. J. Revell, trans. E. J. Revell (The Society of Biblical Literature Masoretic Studies 5; Missoula, Montana: Scholars Press, 1980): 11, 16.

7 This study was born from my own observations regarding the masora circule. Later, I found that Lyons had conducted a substantial survey of the circule placement in A: David Lyons, 'The Masora Circule in the Aleppo Codex' in The Jubilee Volume for Rabbi Mordechai Breuer [Hebrew], vol. 1 (Jerusalem: Academon, 1992): 265-93. Several of the categories I had discerned he, too, found in his work (category 5 and, in part, category 6 below). In several cases he had discerned particular facets of circule use that I had not (categories 1 and 4 below). In concept, then, this article is partly dependent on, and a development of, Lyons' work. In the data pertaining to A, I use Lyons wherever possible. The great bulk of Lyons' article is devoted to this particular scribal habit in A. As an appendix, though, he includes very brief surveys of seven additional MSS, to contextualise the practices he finds in A. These brief surveys are insufficient for the task undertaken in this study, and are referred to only sporadically. The only other scholarly examination of the masora circule known to me is the brief discussion in Glatzer's codicological examination of A: Mordechai Glatzer, 'The Aleppo Codex: Codicological and Paleographical Aspects' [Hebrew], Sefunot 4 (1989): 167-276, see pp. 224-25).

8 A $=$ Aleppo Codex.

$\mathbf{C}=$ Cairo Codex of the Prophets (not examined by the present writer, but briefly surveyed by Lyons).

DP $=$ Damascus Pentateuch.

EVR I Bibl. 54 This MS, now containing large portions of Genesis and Exodus, is part of the Firkowich collection, and only recently made available internationally via the publication of digitised images of the microfilm on the Ktiv website, administered by the National Library of Israel. Yeivin mentions this codex as part of a list of codices from the Firkowich collection worthy of closer study. The codex is oriental, threecolumn, with MP and MM (including collative masora). See Israel Yeivin, The Biblical 
the codices (L and L17) are known to have been written by the same scribe, Samuel ben Jacob. ${ }^{9}$ Comparing the employment of the circule between these two MSS will give some, limited, concrete evidence that the masranim were consistent in their employment of the circule even between different biblical codices. The bulk of the following discussion outlines the seven particular facets of circule placement, and the range of practices found among the sample of MSS. Thereafter, the practices of L and L17 are compared to demonstrate the broad continuity of practice between the two productions. ${ }^{10}$

\section{The Basics of the Masora Circule}

When a scribe or masran added an MP note into the margins, or between the main columns, of a Bible codex, they would customarily mark the particular word or phrase in the biblical text itself with a small circule. Usually, the circule is placed towards the middle of the relevant word, allowing for constraints imposed by the vocalisation and

Masorah [Hebrew] (Studies in Language 3; Jerusalem: The Academy of the Hebrew Language, 2003): 25.

$\mathbf{L}=$ Firkowich B 19a - the 'Leningrad' Codex.

$\mathbf{L 1 7}=$ EVR I Bibl 80 + EVR I B 13; a codex of the Former Prophets written by Samuel ben Jacob, the same scribe behind the production of L. See Phillips, 'New Codex'.

$\mathbf{L 2 0}=$ EVR II B 9. This codex, containing a large proportion of the Latter Prophets, is another item from the Firkowich collection that was mentioned by Yeivin as worthy of further study. Oriental, three columns, MP and MM (including collative masora). See Yeivin, Masorah, 24.

Or. 4445 = 'The London Pentateuch', located in the British Library.

For introductory details, in English, regarding A, C, DP, L and Or. 4445, see Yeivin, Introduction, 15-22.

A, DP, L, and Or. 4445 were chosen for this study because of their great historical significance as high-quality Tiberian masoretic codices. L17 was chosen to enable comparison between it and L, as two productions by the hand of Samuel ben Jacob. EVR I Bibl 54 and L20 were chosen from the list of early oriental masoretic codices mentioned by Yeivin as worthy of significant further study. EVR I Bibl 54 was chosen at random from this list. L20, however, was chosen on account of its similar practice to A with regard to circule placement with qere/ketiv notes (see $\$ 3.1$ below).

9 Phillips, 'New Codex'.

10 For most of the seven issues discussed, data was not gathered across the full sample of MSS. Rather, in each case sufficient MSS were sampled to demonstrate a range of practice with respect to that particular facet of circule placement. Whenever a given MS was sampled, data was gathered across the full extant range of that MS, rather than from a small portion thereof. 
accentuation, and any descenders from the line above, or ascenders from the word itself under consideration. ${ }^{11}$

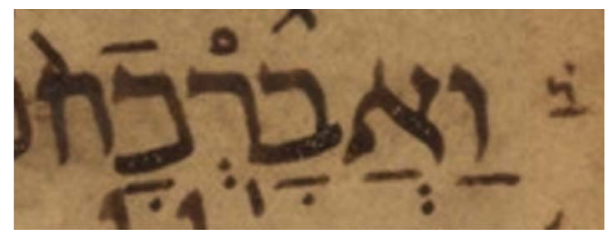

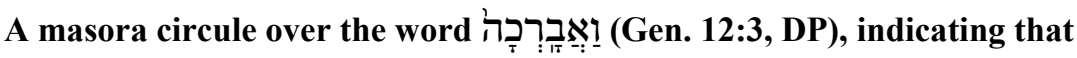
the MP note to the right pertains to this word. In this instance the note is commenting that this particular form of the verb בִּר

Hebrew Bible (Ps. 145:1 is the other location). ${ }^{12}$

If the MP note pertains not to an individual word, but instead to a phrase, circules would usually be placed over the space between each of the words in the relevant phrase.

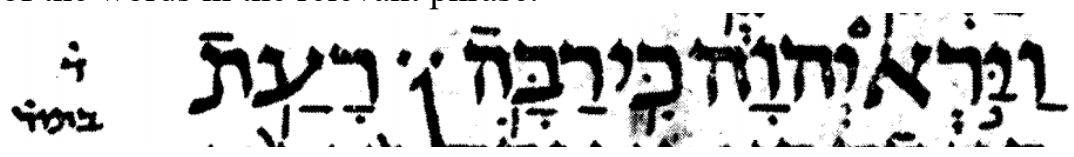

Genesis 6:5 (L). A masora circule over the space between the first two words of the line indicates that the MP note to the left of the line pertains to this two-word phrase וירא יהוה.

\section{Scribal Idiosyncrasies in the Use of the Masora Circule}

This basic pattern of use is modified in various different ways in the oriental codices from the 10th and 11th centuries (and, presumably, in codices from later centuries, though these are beyond the purview of this article). The rest of this article outlines seven such modifications. The first four points below pertain to the use of the circule when used

11 This is simply an approximation, and even here different masranim may display differing habits. Lyons, 'Circule', 5, for example, notes that in the great majority of occurrences in A, the circule appears over the beginning or middle of the word, rather than towards the end of the word.

12 In this article, images from A, DP, and L are taken from public domain PDF versions of these MSS, freely available online. Images of MSS from the Russian National Library are not currently reproducible. In the cases of EVR I Bibl. 54, L17, and L20, therefore, relevant information from the MSS was generally reproduced in electronic form. When a visual representation of the MS data was helpful for the sake of the argument, line drawings were produced based on the relevant data. 
to mark specific types of MP notes. The latter three points all pertain to the placement of the circule when the biblical text being referred to consists of a two-word phrase.

\subsection{Qere/ketiv and the Placement of the Circule}

In the case of qere/ketiv notes, Lyons has demonstrated that the masran behind A had a very pronounced tendency to mark the masora circule over the part of the ketiv word to which the qere reading applied. Thus, at Judges 6:5 we find the ketiv יבאו, with the circule over the initial yod, and the qere note ובאו. On the other hand, at Judges 19:3 we find the ketiv להשיבו, with the circule over the final waw, and the qere note להשיבה. On the basis of small samples, Lyons claims that this same usage occurs in $\mathrm{C}$ and DP. ${ }^{13}$

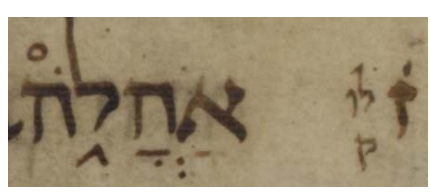

A qere/ketiv note in DP: the circule is marked over the letter $i$, which is the part of the word to which the note refers: the text is to be read אהלו.

On the basis of a broad examination the present writer has found the same marked tendency in L20. By contrast, other MSS, such as L and L17, make no attempt to focus the placement of the circule in this manner.

\subsection{Masora Parva Notes Pertaining to Vowel Counts}

Sometimes, the particular focus of an MP note is to count the number of occurrences of a particular word or form, when it occurs with a particular vowel.

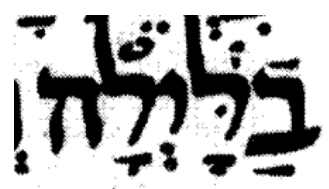

This note in $L$, at Jeremiah 6:5, indicates

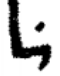
that this is the sole occurrence of the phrase בלילה occurring with qameș under the initial lamed.

As can be seen in the image above, Samuel ben Jacob makes no attempt to mark the circule over the relevant part of the word, such that the reader is left to infer to which vowel the MP note refers (an easy task in this instance, but not always). In some MSS, however particularly L20 in our sample - the masran does attempt to position

13 I have been able to confirm this practice in DP, on the basis of a wide sample, but do not have access to sufficiently high-quality images of $\mathrm{C}$ to perform a larger count. 
the circule over the letter to which the MP vowel note refers. Here are three examples from L20.
Zephaniah 3:5 (L20)
Ezekiel 47:12 (L20)
Ezekiel 43:24 (L20)

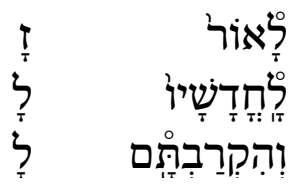

In each of these cases the MP note counts the number of times a certain

form occurs with a qameș vowel. In each case, $L 20$ clarifies the note by placing the circule over the relevant consonant.

This feature was sampled across A, DP, EVR I Bibl 54, L, L17, L20, and Or. 4445, with only L20 specifying the circule's location in this manner. Even in L20, however, this feature is only a marked tendency, rather than an unbreakable rule. ${ }^{14}$

\subsection{Plene/Defective}

On the basis of the above, one might have expected that, when marking a plene/defective MP note on a word, at least some MSS would mark the mater lectionis in question (or lack thereof) by placing the circule over that letter/space. Surprisingly, this does not appear to have been a major tendency, even among A, DP, and L20 (which all show special attentiveness to the circule's placement in qere/ketiv cases). Lyons specifies with regard to A: 'The particular placement [of the circule] within the boundaries of the word carries no significance at all with respect to the masoretic note pertaining to that word, except in one type of note alone: the qere/ketiv notes. ${ }^{15}$ Similarly, in DP, L, and L17 I found no particular sensitivity in the placement of the circule when dealing with notes on plene/defective spellings. Only in L20 does the masran appear to show any attentiveness in this regard, and even then only as a minor tendency.

In many notes the circule appears over the relevant letter, but it is hard to be sure that the placement was intentional.

Isaiah 5:8 (L20)

ל ומל

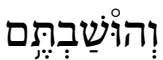

In this, and many other, cases, the circule does appear over the mater lectionis to which the MP note refers. However, the placement is

14 In a sample of 56 occurrences throughout the codex, the circule was placed over the relevant letter in 38 instances (just over $2 / 3$ of the sample). In 18 of those 38 instances the circule position involved an obvious degree of intentional placement.

15 Lyons, 'Circule', 269. 
sufficiently close to the standard central location for the masora circule that it is hard to be confident that such a placement was intentional.

In many cases, however, it is hard to see the placement of the circule as anything other than intentional, particularly when compared to the same note in other codices.

Isaiah 2:6 (L20) ذ חד חס וחד מל

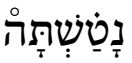

The circule over the heh clarifies that the MP note refers to that letter. There are only two occurrences in the Hebrew Bible of the $2 \mathrm{~ms}$ perfect qal of the root נ־־, without an object suffix. The other occurrence is at 1 Samuel 17:28, and lacks the final heh.

Isaiah 4:5 (L20) לוחס

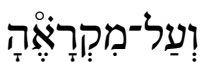

In the MS itself, the circule appears directly over the space between the alef and the heh.

The circule between the alef and the heh in L20 above clarifies that the defective spelling of this word pertains to the plural yod that might otherwise have been placed here. Contrast the placement found in A:
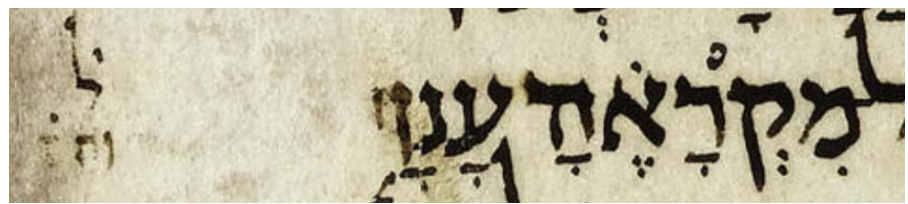

From Isaiah 4:5 in A. In this case, the placement of the circule offers no help in the interpretation of the same MP note.

A particularly probative demonstration that the masran behind L20 felt some inclination to 'link' the circule with the relevant mater lectionis, whereas the masran behind A felt no such inclination, can be found at Isaiah 55:8 in these two codices.
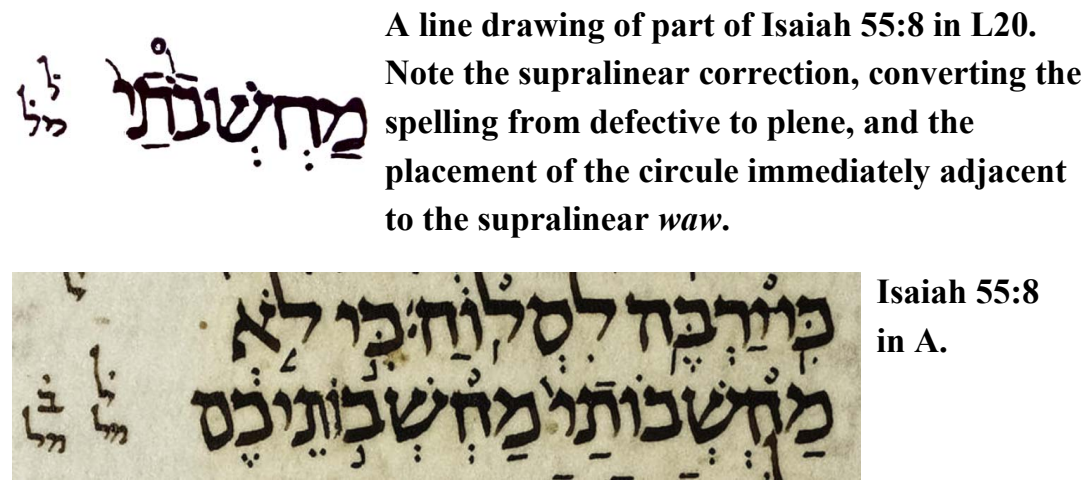

Isaiah 55:8

in $\mathbf{A}$. 
In both codices, the masran emends an incorrect spelling. In L20 the masran corrects the defective מחשבתי to the plene מחשבותי by adding a small supralinear waw. Note in particular how the masran marked the masora circule in close proximity to this supralinear waw, as if by way of clarification for the correction. By contrast, in A the masran corrects the defective מחשבתיכם to the plene מחותיכם by the common technique of severing the right-hand leg of the tav and converting it into a waw. Nonetheless, the circule connecting the word to the note that precipitated the correction is marked at the very beginning of the word, nowhere near the correction itself.

\title{
3.4 Circule Placement in Instances of MP Notes Referring to Entire Verses
}

Mostly, the MP consists of notes pertaining to individual words, forms, or phrases. However, a substantial subset of the MP consists of notes that refer not to any individual element in a verse, but to the entire verse itself. Typically, the verse will contain a particular syntactic structure, and the MP note will count the total number of verses in the Hebrew Bible (or a specified subset thereof) with that same structure. An easy, and characteristic, example is found in L (f. 4r), referring to ; ביניה: 'There are 12 verses (in the Hebrew Bible) containing a string of 3 object markers, where the third instance is preceded by waw, where each object marker is separated from the next by precisely one word.'

Apparently, the masranim were keenly aware of the different quality to these whole-verse MP notes, compared to the other MP notes; their practices regarding circule placement for this type of note are, in some codices, quite distinct from their usual practice. Once again, the various choices made by the masranim in this situation afford room for individuality and idiosyncrasy.

\begin{abstract}
Aleppo
Lyons' study of this phenomenon in A produced the following results. ${ }^{16}$ In a sample of 31 instances, the circule is used in 30 of those instances. The major tendency $(24 / 30)$ is to place the circule at the beginning of the relevant verse. A minor tendency $(6 / 30)$ is to place the circule over one (or occasionally more) of the biblical words referred to
\end{abstract}

16 Lyons, 'Circule', 287-89. 
in the note itself. In the Genesis 5:32 example above, this would mean placing the circule over one or more of the occurrences of the word את.

Lyons gives further detail in his description of the major tendency. In 18 out of the 24 instances the circule is placed directly over the first word of the relevant verse. In the remaining instances the circule appears to the left of this ideal position, over the space between the first two words, or over the second word. In one instance the circule is displaced to the supralinear space over the third word of the verse.

\section{Damascus Pentateuch}

In a sample of 20 instances of these particular types of notes, taken throughout the full breadth of the codex, 16 of the notes were marked with a circule, while 4 notes were not 'attached' to the verse by a circule. Of the 16 notes marked with a circule, 13 of the circules were attached to one of the biblical words referred to by the note itself. Thus, the minor tendency in A is the major tendency in DP. The other 3 circules were written over the first word of the verse. ${ }^{17}$ Of the 4 notes lacking a circule, 3 were written adjacent to one of the words referred to by the note itself, and one was written adjacent to the beginning of the biblical verse. The omission of a circule in these cases appears, therefore, to be purely accidental.

\section{Leningrad}

Unlike A and DP, L tends not to use a masora circule for this type of note (13/20 occurrences do not have a circule). In the 7 instances where a circule is used, $3 / 7$ appear over the first word of the verse, and 4/7 appear between the first and second words of the verse.

\section{L17}

The tendency not to use a masora circule for this type of note is more pronounced in L17: 18/20 examples do not employ a circule. In the two examples where a circule does appear, it occurs over the first word of the verse.

17 In fact, one of these three was written over the fourth word of the verse, but this appears to be due simply to the verse's beginning at the end of a previous column, and the note being written at the top of the following column. 


\section{Or. 4445}

In this MS, the circule was not used in any of the 20 sampled instances of this type of MP note.

The descriptions above show two choices being made by the masranim in the case of MP notes referring to entire verses. (1) Should a circule be used in these cases at all? (2) If a circule is used, should it be marked at the beginning of the verse, or over one of the relevant words in the verse referred to by the MP note itself? ${ }^{18}$

\subsection{Internal Circule Placement}

When the MP note refers to a two-word phrase, both words of which lie on the same line, the masora circule is usually placed over the space between the two words (see $\S 2$ above). However, in the MSS examined the circule is sometimes placed between the two words. Below, I refer to this as internal circule placement (ICP).

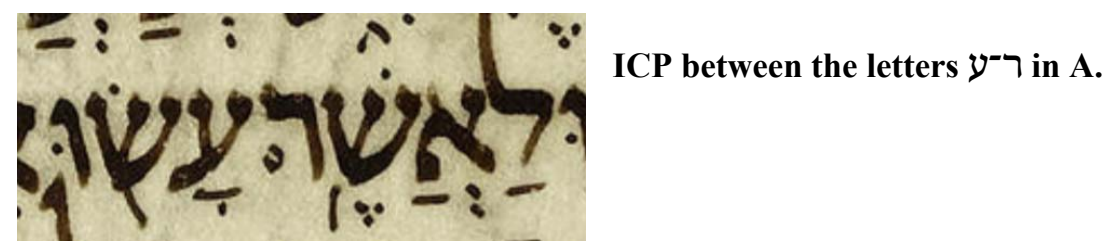

The table below displays the results of an examination of the extent to which ICP is found in A, DP, EVR I Bibl 54, L, L17, and Or. 4445. ${ }^{19}$

18 In the MSS that tend not to mark a circule for these notes, a subsidiary question arises. When a circule is marked in a MS, the MP note necessarily appears adjacent to the circule. Yet if no circule is marked, where ought the MP note itself begin? Three options are available to the masran: to begin the note adjacent to the beginning of the biblical verse; to begin the note adjacent to one of the occurrences of the biblical word relevant to the MP note; or to simply write the note adjacent to the biblical verse, without respect to the verse's beginning, or to the occurrences of the words relevant to the MP note. Initial surveys of the MSS suggest that this, too, was a matter of scribal choice and consistency. In Or. 4445, for example, the masran appeared to have a preference $(15 / 20$ occurrences) for marking the MP note adjacent to one (usually the first) occurrence of the relevant word. By contrast, L20 shows a preference $(15 / 20$ occurrences) for beginning the MP note adjacent, or as close as possible, to the beginning of the relevant verse.

19 The count was conducted as follows. Starting at the beginning of each codex, an ordered search was conducted for every MP note pertaining to (at least) a pair of words, where that pair of words were each located on the same line. The supralinear or internal placement of the circule was then noted. The count continued until ten data points had been collected. This procedure was then iterated at four other points throughout the codex in question, so that the data was gathered in five clusters of ten 
Number of internal circule placements (/50) for each MS

\begin{tabular}{|c|c|c|}
\hline MS & $\# / \mathbf{5 0}$ & Pair of letters between which the circule is placed \\
\hline Or. 4445 & 39 & 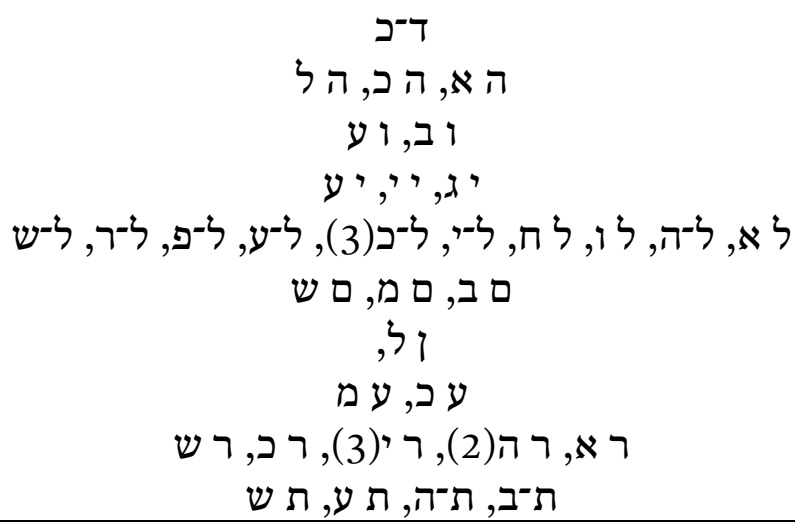 \\
\hline $\mathrm{L}$ & 16 & ל־ב(2), ל־ד, ל־ה(2), ל־י(2), ל־כ, ל־מ(2), ל־ע, ל־פ \\
\hline L17 & 10 & ל א(3), ל־ה, ל ח, ל־י, ל־מ, ל־ע \\
\hline A & 5 & ל ה, ל-ע כ ד \\
\hline $\begin{array}{l}\text { EVR I } \\
\text { Bibl. } 54\end{array}$ & 2 & ל־ה, ל ש \\
\hline DP & 2 & ל־א, ל־ה \\
\hline
\end{tabular}

The data above reveal a wide range of practice among the sampled MSS. At one end of the spectrum, some MSS (notably Or. 4445 in this sample) frequently and freely place the circule within the space between the two words. At the other end of the spectrum, some MSS (notably DP and EVR I Bibl. 54 in this sample) almost never place the

across the full range of the codex. In the case of all searches carried out in Or. 4445, the search was only conducted across the text-range of the extant original MS, rather than including the later Yemenite material. 
circule within the space between the two words, preferring the more standard supralinear placement. The other MSS fall somewhere between these extremes.

To some extent, the supralinear versus internal placement appears to be dependent on spatial considerations: MSS with a high line density have less space between lines, and this may sometimes have forced the masran to note the circule internally. However, it is important to see that supralinear versus internal circule placement is not purely a corollary of line density. Examination of virtually any page of Or. 4445 (21 lines per column) will reveal examples of ICP that are not motivated by lack of supralinear space. By contrast, on many pages of A (28 lines per column) the masran prefers to squeeze the circule into the already crowded supralinear space rather than utilise the natural cavity formed by the letters lamed, resh, and dalet. Thus, the extent of ICP in these MSS appears to be at least partly a matter of scribal preference.

The considerations of the previous paragraph also pertain, mutatis mutandis, to the choice of letter pairs within which ICP occurs. Presumably the frequency with which ICP occurs when $ל$ is the first letter of the pair (in all the MSS surveyed) is a corollary of the fact that the upstroke of the $ל$ (which frequently leans to the left in these MSS) partially obscures the available space for the supralinear circule, while the cavity formed by the lower part of the letter simultaneously affords the circule a suitable place of refuge. Again, however, spatial considerations cannot be the full explanation: in each of Or. 4445, L, L17, and A, ICP occurs even with letters that neither obscure the supralinear space nor afford a convenient line-internal cavity. Again, scribal preference appears to be at work.

\subsection{Two Words Straddling Two Lines: Position of the Circule and MP Note}

Above (§3.5) we considered the placement of the circule when an MP note refers to a two-word phrase, where both words fit onto the same line. Frequently, however, a two-word phrase referred to by an MP note does not fit in its entirety onto the same line. Rather, the first word occurs at the end of a line, and the second follows at the beginning of the subsequent line. The scribe then faced a choice as to where to position the masora circule: at the end of the first line, following the first word, or at the beginning of the second line, preceding the second 
word (or even to use two circules, one in each of these positions). Again, individual scribes display distinct tendencies.

An additional factor to be considered alongside the placement of the circule is the placement of the MP note itself: does the placement of the circule correlate with the side of the column on which the note is marked? Does the scribe fix the side on which the MP note appears? These sorts of considerations afford a surprisingly wide field for individual scribal choice, as is demonstrated below. ${ }^{20}$

\section{Or. 4445}

In this MS the circule is consistently placed on the left-hand side of the column, after the first word of the pair. ${ }^{21}$ However, Or. 4445 shows a strong tendency to place all the MP notes on the right-hand side of the column in which the pertinent word or phrase appears. ${ }^{22}$ Thus, though the circules under discussion virtually always appear on the left-hand side of the column, the attached note appears to the right of the column.

\section{EVR I Bibl. 54}

In this MS, too, the circule consistently appears to the left of the column (i.e. after the first word of the pair). Moreover, like Or. 4445 there is a strong tendency for all MP notes to be positioned to the right of the pertinent column. As the MP notes are more sparse in this MS than in Or. 4445, I found no exceptions to this rule.

The remaining four MSS all place the masora circule on either the left- or right-hand side of the column (i.e. either immediately following the first word, or immediately preceding the second word). In each case, a sample of fifty occurrences was taken, spread throughout the full range of each MS.

\footnotetext{
20 Lyons, 'Circule', 280-81 also considers the placement of the circule in A when the two-word biblical phrase is divided over two lines. However, he focuses predominantly on the $\mathrm{L} / \mathrm{R}$ placement of the circule and the height of the circule, rather than correlating the circule placement with the MP note itself. In this instance, therefore, I was not able to use Lyons' data.

21 In a sample of approximately 40 instances, I only found one instance of the circule appearing on the right-hand side of the column, preceding the second word of the pair. This occurred when the pair straddled not just a line, but an entire column. The circule appeared to the right of the second word of the pair, which formed the first word of a new column.

22 Generally, it appears that MP notes are only placed to the left of the column when the appropriate space to the right of the column has already been used (for example, by a long previous note).
} 


\section{Leningrad}

MP note on left

Circule on left

7

3
Circule on right

0

40

A clear preference in $\mathrm{L}$ appears to be the placement of both the circule and the corresponding MP note, on the same side of the column (47/50 cases). Also a clear preference in L is that the MP note appear on the right-hand side of the column (43/50 cases). Of the seven cases where the note appears on the left, most of these are explicable on spatial grounds: the preferred space on the right-hand side of the column was already taken up by another MP note. From the data above it is not possible to determine which of these two preferences is dominant in L. Therefore, a further sample was taken consisting of 20 instances when the circule is marked on the left of the column. In 18 of these instances, the MP note is also marked on the left of the column, in proximity to the circule. Thus, it appears that the aim of placing both the circule and the corresponding MP note on the same side of the column is of greater significance to L than having the MP note on the right-hand side of the column. ${ }^{23}$

\section{$\mathbf{L 1 7}$}

MP note on left

Circule on left

23

MP note on right

0
Circule on right

0

27

The clear and consistent ruling tendency in L17 is the aim of placing both the circule and the corresponding MP note on the same side of the column (50/50 cases). Apparently, there is no significant preference as to which side of the column the circule and note appear.

\section{Damascus Pentateuch}

$\begin{array}{llll} & \begin{array}{l}\text { Circule } \\ \text { on left }\end{array} & \begin{array}{l}\text { Circule } \\ \text { on right }\end{array} & \begin{array}{l}\text { Circule on } \\ \text { left AND right }\end{array} \\ \text { MP note on left } & 8 & 0 & 0 \\ \text { MP note on right } & 8 & 30 & 4\end{array}$

23 It should be noted that, occasionally, L marks the masora circule on both the leftand right-hand side of the column. These occurrences are rare, and none happened to occur in the sample. 
The ruling tendency in DP appears to be the desire to place the MP note on the right-hand side of the column (42/50 cases). The great majority of the exceptions to this tendency arise because the relevant space on the right-hand side of the column has already been taken up with another MP note. The two most obvious differences between DP and $L$ are: (i) DP's greater readiness to place the masora circule on the left-hand side of the column (20/50 cases in DP versus 10/50 cases in L), and (ii) DP's occasional use of two circules, one following the last word of the first line, the second preceding the first word of the next line.

$\begin{array}{llll}\text { Aleppo } & \text { Circule } & \begin{array}{l}\text { Circule } \\ \text { on right }\end{array} & \begin{array}{l}\text { Circule on } \\ \text { left AND right }\end{array} \\ \text { MP note on left } & 9 & 0 & 0 \\ \text { MP note on right } & 11 & 27 & 3\end{array}$

The tendencies in A are very similar to those in DP. Again, the driving tendency appears to be the placement of the MP note on the right-hand side of the column (41/50 cases). However, of the nine cases where the MP note appears on the left of the column, it appears that in at least five of them the note could have appeared on the right-hand side of the column without undue cramping. A shows a similar, or even more pronounced, willingness to that found in DP to place the masora circule on the left-hand side of the column (23/50 cases). Finally, again like DP, A occasionally uses two circules (one following the last word of the first line, the second preceding the first word of the next line).

The evidence above suggests that in this particular minute consideration of the placement of the masora circule, there is again sufficient scribal idiosyncrasy, and scribal consistency, to include this feature among the various paratextual features by means of which individual MS leaves can be regathered, and by means of which the work of individual scribes can be determined. For example, by means of this feature alone, any page from Or. 4445 could be distinguished from any page of L17, or any page of A. ${ }^{24}$

24 It is likely that the analysis could be extended to even more fine-grained considerations than those above. For example, one factor not considered above is whether the phrase targeted by the MP note consists of two, or more than two words, and how this affects the placement of the masora circule (Lyons, 'Circule', discusses these cases with respect to A). Almost all of the locations sampled in L where the 


\subsection{Two Words Straddling Two Lines and Joined by Maqqef: The Position of the Circule Relative to the Maqqef When Both Occur at the End of a Line}

Let us continue further down the rabbit hole. On occasion, the twoword phrase, crossing from one line to the next, is joined by maqqef. In this situation the masran is faced with the question of where to place the circule relative to the maqqef. Yet again, at least some of the MSS show clear tendencies.

\section{Or. 4445}

In keeping with his strong tendency towards internal circule placement (§3.4), the circules appearing to the left of the column generally appear at the mid-height of the preceding letter, and below a conjoined maqqef $(22 / 25)$. Very rarely $(3 / 25)$, the circule appears above the maqqef, at the mid-point thereof. ${ }^{25}$
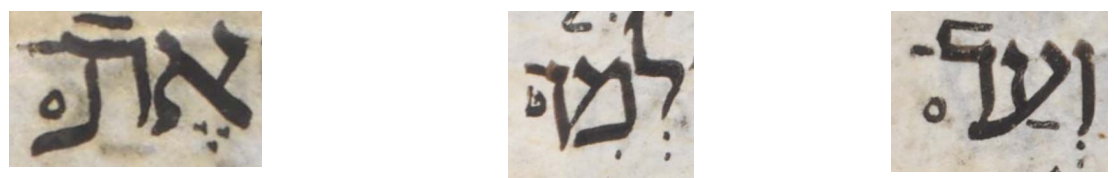

\section{Leningrad}

When the circule appears on the left, and there is also a maqqef, the circule is consistently (though not without exception) positioned at the left-hand end of the maqqef, at the same height thereof, or marginally lower. This appears to be a corollary of a basic intention of 'hanging' these end-of-line circules from the ruled guideline (which are difficult to discern in black and white reproductions). As a result, the circule is positioned at the same height as the level of the upper horizontal strokes of the letters ב ב, ד, ה etc.
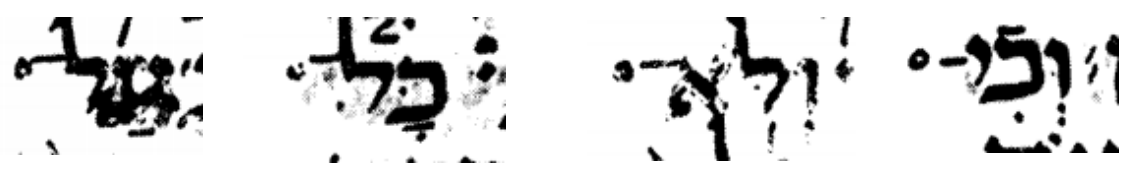

circule is placed on the left of the column, but the MP note is located on the right of the column occur when the MP note is targeting a chain of more than two words. The individuality demonstrated by some of the codices in the sample above is more than sufficient to demonstrate the claim of this article, but it may well be that paying attention to the length and position of annotated phrases longer than two words would demonstrate yet more intentionality and consistency.

25 Images (C) British Library Board (Or. 4445: f.32v, f.50v, f.65v). Used with permission. 


\section{L17}

Samuel's practice of correlating maqqef and circule, when they both occur at the end of the line, is similar, but not identical, to his practice in L. As in L, his basic aim is to position the circule at the same height as the level of the upper horizontal letter strokes. In many instances this is achieved in the same manner as in L: the circule appears at the lefthand end of the maqqef. However, with the letter ' Samuel's practice in L17 is slightly different to that seen in L. By raising the height of the maqqef, such that it protrudes from part-way up the ascender of the letter, he gains sufficient room to position the circule beneath the maqqef, such that the circule is still at the same height as the level of the upper horizontal letter strokes.

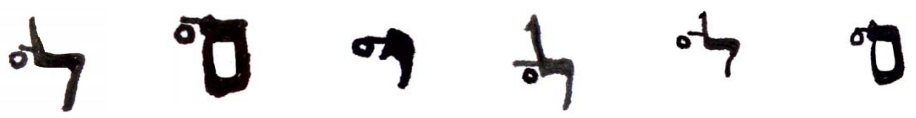

\section{L20}

Unlike L and L17, the basic tendency in L20 is for the circule to be positioned above the height of the upper horizontal letter strokes $(23 / 25$ occurrences). Usually, the circule appears above and to the left of the maqqef (14/25 occurrences). Alternatively, it appears directly above the maqqef ( $9 / 25$ occurrences).

In a very small minority of cases $(2 / 25)$, the circule appears below the maqqef, at the mid-height of the letter. In both occurrences of this positioning in the sample, the circule in question was preceded by another circule positioned internally. Plausibly, it was the ICP of the preceding circule(s) that conditioned the lowering of the line-end circule.
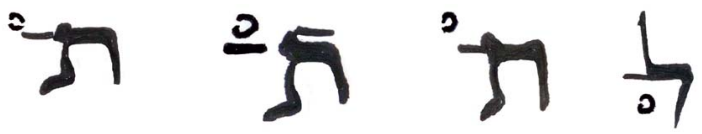

\section{Damascus Pentateuch}

The practice in DP is very similar to that of L20. When a circule and maqqef coincide at the left edge of the column, DP employs two basic patterns: either the circule appears at the left-hand end of the maqqef, or it appears at the midpoint of the maqqef, above the line.
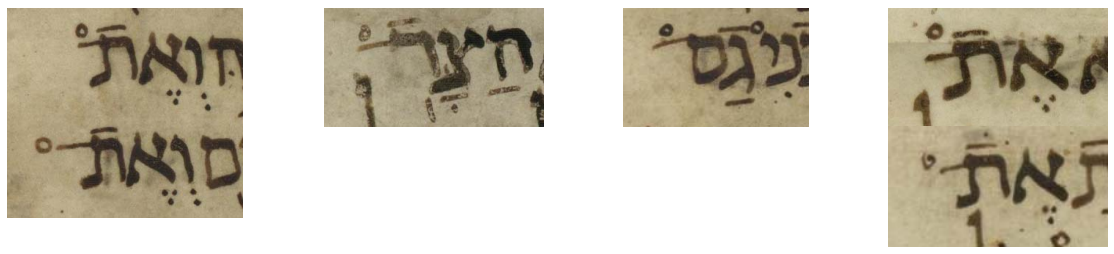


\section{Aleppo}

When a circule and maqqef coincide at the left edge of the column, the most common arrangement is for the circule to appear just off the lefthand end of the maqqef, and slightly above it (generally not touching the maqqef). However, there is much variation: sometimes the circule appears above the maqqef at the midpoint of the maqqef; on other occasions it appears below the maqqef.
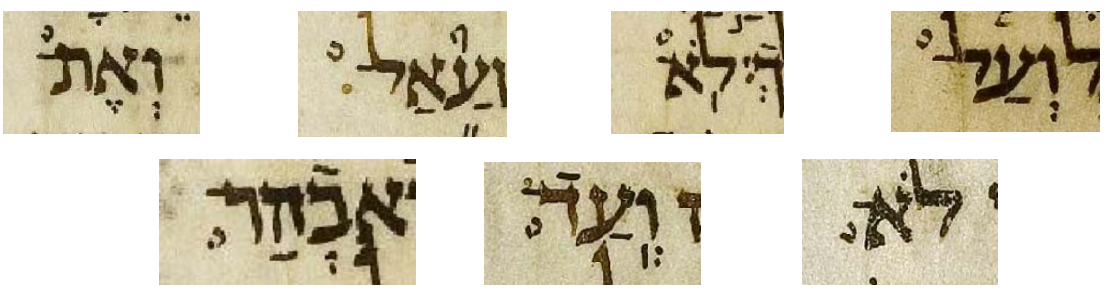

\section{Observations}

Even at this detailed level, some of the scribes behind these MSS show a remarkable degree of intentional decision-making and consistency in circule placement. Most obvious in this respect is Samuel ben Jacob. Throughout L and L17, he consistently places the end-of-line circule at the same height as the level of the upper horizontal letter strokes. This is particularly noteworthy in that only these extra-columnar circules (either on the left or right of the column) are placed at this height. Intra-columnar circules are either supralinear, or else placed 'internally'. Samuel's practice is clearly distinguishable from that of Or. 4445 on the one hand and from the practice in L20, DP, and A on the other hand: the former consistently locates the circule below the maqqef, while the latter MSS show a marked tendency to place the circule above the maqqef.

\subsection{Summary}

The discussion above has presented seven different facets of the employment of the masora circule. The first four points pertain to the use of the circule when referring to different types of MP notes (qere/ketiv, vowel counts, plene/defective, notes pertaining to entire verses). The latter three points pertain to different spatial considerations in the placement of the circule when the MP note refers to a two-word phrase in the biblical text.

How does the evidence above corroborate the first three of the four claims outlined in the introduction? First, it is clear that for each of the 
seven issues discussed above, a range of scribal practices can be discerned among the MSS. ${ }^{26}$ The only features that could be questioned in this respect are the tendency to locate the masora circule in the vicinity of a relevant mater lectionis (or the vicinity of the lack thereof) in the case of plene/defective notes, and the tendency with vowel count MP notes to mark the circule over the relevant consonant. These features were found only in L20 and could, therefore, be argued to be idiosyncrasies of that MS alone. On reflection, however, it seems rather implausible that we should have stumbled across the only MS with these features, given that these two facets of L20's circule placement were discovered only after the decision was made to examine this particular MS. More likely, these features will, in due course, be found to be characteristic of other codices as well.

Second, the issue of consistency. The evidence above does not support the claim that each MS is fully consistent in its practice with respect to each of the seven issues discussed. What can be claimed is sufficient consistency among each of the MSS across the full range of facets regarding circule placement such that meaningful distinctions can be made between the various MSS. This ties in to the third claim: when taken together, these seven facets demonstrate significant capacity to distinguish between different biblical codices. That is, a MS's practice across the range of these seven features forms a 'fingerprint' for that MS that distinguishes it from all the other MSS in the sample. ${ }^{27}$ Let us consider A, DP, and L20. These MSS are all similar in the matter of circule placement with maqqef, and in their marking of the circule with respect to qere/ketiv notes. Nonetheless, simply adding in consideration of their practice when dealing with MP notes referring to entire verses is sufficient to distinguish between the three MSS. As another example, Or. 4445 and EVR I Bibl. 54 are very similar in their habit of placing the circule on the left, but the MP note on the right, in cases where a two-word phrase crosses from one line to the next. Nonetheless, consideration of their practice in circule placement when the two-word phrase falls on a single line decisively

26 Note that this does not mean that all the different MSS behave distinctively regarding each of the seven issues. For example, A, DP, and L20 were all very similar in the matter of circule placement with maqqef. However, this is not a defeator for the current argument. For the current argument, it is sufficient if each of the seven features reveals a clear spectrum of practices, such that MSS at either end of the spectrum are clearly distinct one from the other. This is clearly the case.

27 With the exception of L and L17, both written by Samuel ben Jacob. See infra. 
distinguishes between the two. In the same way, any two of the MSS sampled can be distinguished when the full gamut of issues relating to circule placement are considered, with the exception of L and L17.

\section{Circule Placement in L and L17}

L and L17 are both the work of Samuel ben Jacob. These codices, therefore, afford a useful opportunity to examine whether one scribe's habits regarding the masora circule in one codex transfer equally to his habits in a different codex. The table below summarises the data from the previous discussion.

$\mathrm{L}$

1. Qere/ketiv No special placement

2. Vowel counts

3. Plenel defective

4. Whole-verse 13/20 no circule MP notes

5. ICP

6. Two-word phrase across two lines

7. Circule + maqqef
No special placement

No special placement

No special placement

18/20 no circule

$10 / 50$

Circule and note on same side of column. No preference for notes on RHS of column

Circule at LH end of maqqef, hanging from ruling line

In broad outline, it seems that Samuel's practice regarding circule placement is indeed approximately the same between codices, and demonstrably different, when taken together, from the other codices sampled. In the case of L and L17, their treatment of circule and note placement when a two-word phrase crosses from one line to the next, and their treatment of the collocation of circule and maqqef, are 
particularly probative. This provides encouraging (albeit limited) evidence that circule placement as a paratextual feature of Tiberian Bible codices can be added to the growing list of features not only for reuniting separated leaves from the same codex, but also for identifying other MSS written by a known scribe. ${ }^{28}$

\section{Conclusions}

Can masora circule placement habits be thought of as another of BeitArié's so-called paratextual features, by means of which the work of individual scribes can be distinguished and identified, and separated portions of a single codex reunited? The data presented here suggest that the answer is yes. The different facets of circule placement, considered together, form a fingerprint sufficiently unique to distinguish each of the MSS in the sample above one from the other, and sufficiently similar in the case of two codices known to have been written by the same scribe.

The discussion above suggests that this tool will be most useful when at least several leaves of a quire are available for examination. The more text is available, the more opportunities will be afforded to build a rounded view of the MS's circule placement habits. This does not mean that this is an inappropriate tool for use with the Genizah fragments; only that it is less predictable in terms of its possible utility. For each of the MSS in the sample, it transpires that a couple of the facets are particularly distinctive of that MS. For example, if we were to find a fragment, separated from one of the codices above, in which the circule, appearing at the end of a line of text, in collocation with a maqqef, was positioned at the left end of the maqqef, hanging from the ruling line, this would be strong evidence linking the fragment to either $\mathrm{L}$ or L17. As with all the other paratextual features, there is an element

\footnotetext{
28 The table, together with the longer discussions above, reveal various differences in the treatment of the circule between the two codices. It is likely that many of these differences are to be explained by the very different formats and layouts of these two codices. For example, L17 shows a marked decrease in the use of internal circule placement compared to L. This may be explicable in terms of line density. L17 is written with just 17 lines per $27 \mathrm{~cm}$ high column, whereas L contains 27 lines per 20.5 $\mathrm{cm}$ high column. Frequently in L, therefore, ICP can be seen as a practical necessity: the relevant supralinear space already contains a vowel or accent mark. Such cramping is far less of an issue in L17, and few, if any, of the occurrences of ICP are explicable on this ground alone.
} 
of serendipity involved in terms of which features will occur in which fragment. This is why the palaeographer's paratextual toolkit must be as full as possible. 